\title{
Transcriptional regulation of the mouse steroidogenic acute regulatory protein gene by the CAMP response-element binding protein and steroidogenic factor 1
}

\author{
P R Manna, D W Eubank, E Lalli ${ }^{1}$, P Sassone-Corsi ${ }^{1}$ and D M Stocco \\ Department of Cell Biology and Biochemistry, Texas Tech University Health Sciences Center, Lubbock, Texas 79430, USA \\ ${ }^{1}$ Institute de Génétique et de Biologie Moléculaire et Cellulaire, Centre National de la Recherche Scientifique, Université Louis Pasteur, B.P. 163, \\ 67404 Illkirch, Strasbourg, France
}

(Requests for offprints should be addressed to D M Stocco; Email: doug.stocco@ttmc.ttuhsc.edu)

\begin{abstract}
Transcriptional induction by CAMP is mediated through the interaction of the CAMP response-element binding protein (CREB) with a CAMP response element (CRE) in the promoter of target genes. The steroidogenic acute regulatory (StAR) protein gene is regulated by CAMP-mediated signaling in steroidogenic cells even though its promoter lacks a consensus CRE. Previously, we have identified three highly conserved $5^{\prime}$-CRE half-sites within the $-96 /-67$ bp region of the mouse StAR gene, and a member of the CREB family (CREB/CRE modulator (CREM)) was shown to be involved in its expression and regulation. Here we show that CREB and $C R E M \tau$ (but not CREM $\alpha$ and $C R E M \beta$ ) have qualitatively similar effects on StAR promoter activity in response to $(\mathrm{Bu})_{2} \mathrm{CAMP}$. Studies on the effects of the functional integrity of the CRE half-sites on CREB-dependent $(\mathrm{Bu})_{2} \mathrm{CAMP}$-mediated StAR gene transcription demonstrated the greater importance of the CRE2 site in comparison with the CRE1 and CRE3 sites. The CRE2 sequence was also found to bind specifically to recombinant CREB protein and nuclear extract from MA-10 mouse Leydig tumor cells. The CAMP and CREB/CREM responsive region $(-151 /-1 \mathrm{bp})$ of the mouse StAR promoter also contains three recognition motifs for steroidogenic factor 1 (SF-1). Electrophoretic mobility shift assays and reporter gene analyses demonstrated the involvement of different SF-1 elements in StAR gene expression with the order of importance being SF-1/3>SF-1/1>SF1/2. Specific mutations that eliminated the binding sites of CRE and SF-1 elements, either alone or in combination, resulted in an attenuation of StAR promoter activity, indicating that CREB and SF-1 can regulate StAR gene transcription in a cooperative fashion. In addition, mammalian two-hybrid assays revealed a high affinity protein-protein interaction between CREB/CREM $\tau$ and SF-1 which appeared to be dependent upon CREB protein phosphorylation. These findings further demonstrate CREB's role in StAR gene transcription and also provide evidence that the combined action of CREB/CREM $\tau$ and SF-1 results in enhanced activation of the StAR promoter.
\end{abstract}

Journal of Molecular Endocrinology (2003) 30, 381-397

\section{Introduction}

The steroidogenic acute regulatory (StAR) protein mediates a key step in the regulation of steroid hormone biosynthesis in steroidogenic tissues, i.e. the delivery of cholesterol from the outer to the inner mitochondrial membrane (Privalle et al. 1983, Clark et al. 1994, Waterman 1995, Stocco \& Clark 1996). The expression of StAR protein in the adrenals and gonads is induced by cAMP, and is intimately correlated with the acute steroidogenic response of these cells to tropic hormone stimulation (Epstein \& Orme-Johnson 1991, Stocco \& Clark 1996). It has been demonstrated that inhibition of transcription markedly affects synthesis of the StAR protein and steroid biosynthesis in mouse Leydig cells (Stocco \& Clark 1996, Clark et al. 1997, Manna et al. 2001). Regulation of 
cAMP-dependent StAR expression and steroidogenesis involves transcriptional induction; however, the StAR gene promoter lacks a consensus cAMP response element (CRE) and, as such, resembles the promoter of several steroid hydroxylase genes that are regulated by cAMP (Waterman 1994).

The mechanism of cAMP signaling at the gene level is mediated through an eight-base pair (bp) palindromic sequence (5'-TGACGTCA-3') which is referred to as the CRE (Montminy et al. 1986, Meyer \& Habener 1993, Lalli \& Sassone-Corsi 1994). However, studies have demonstrated that the 5'-TGACG part of the palindrome is highly conserved with respect to the 3'-TCA (SassoneCorsi 1995). To date, several CRE-binding factors have been characterized, including the cAMP response-element binding protein (CREB), the CRE modulator protein (CREM) and activating transcription factor (ATF-1) (Sassone-Corsi 1995). CREB, GREM and ATF-1 are members of a basic-leucine zipper (bZIP) family of transcription factors, which contain basic DNA binding and transactivation domains both in the basal and cAMP-induced state (Yamamoto et al. 1990, Quinn 1993). The functions of these CRE-binding proteins are modulated after phosphorylation by the cAMP-dependent protein kinase A (PKA) and other kinases (Montminy et al. 1986, Quinn 1993). The cAMP-mediated increases in transcription are observed only after the phosphorylation of CREB or CREM at serine -133 or -117 respectively, and its specific binding to a nuclear protein CREB binding protein (CBP) (Gonzalez \& Montminy 1989, Chrivia et al. 1993). We recently identified three CRE half-sites in the proximal region of the mouse StAR gene, and the involvement of CREB/CREM in increasing steroid synthesis and StAR expression was investigated using different approaches that affected CREB/CREM function (Manna et al. 2002a). It has been demonstrated that through alternative splicing CREB and CREM genes exhibit several isoforms, which act as both activators and repressors of transcription (Lee \& Masson 1993, Sassone-Corsi 1995).

The StAR promoter sequences in mouse, rat, and human are highly homologous, with the region involved in regulation by cAMP possessing recognition sequences for several transcription factors, including steroidogenic factor 1 (SF-1) (Sugawara et al. 1996, Caron et al. 1997, Sandhoff et al. 1998, Reinhart et al. 1999, Wooton-Kee \& Clark 2000). SF-1 is a member of the orphan nuclear receptor superfamily that has been shown to be involved in the cAMP-regulated expression of many steroidogenic genes, including the cholesterol side chain cleavage enzyme (Zhang \& Mellon 1996, Liu \& Simpson 1997), aromatase (Lynch et al. 1993, Carlone \& Richards 1997), the adrenocorticotropin receptor (Cammas et al. 1997), and DAX-1 (dosage-sensitive sex reversal-adrenal hypoplasia congenita critical region on the $\mathrm{X}$-chromosome) (Yu et al. 1998). Several PKA-dependent phosphorylation sites have been found within the SF-1 protein and are instrumental in its function (Carlone \& Richards 1997, Jacob \& Lund 1998, Hammer et al. 1999). SF-1 has also been demonstrated to play important roles in mediating StAR gene expression (Sugawara et al. 1997, Sandhoff et al. 1998, Reinhart et al. 1999); however, its mechanism of action remains poorly understood.

Since the StAR gene lacks consensus CREs, the mechanism of its regulation by cAMP is of considerable interest. The identification of three well conserved CRE half-sites presented the opportunity to understand this mechanism in more depth. The present investigation was undertaken to determine if CREB/CREM could interact with SF-1 to regulate StAR gene expression. Taken together, these findings provide the first evidence that cooperation between CREB/CREM $\tau$ and SF-1 is required for transactivation of the StAR gene.

\section{Materials and methods}

\section{Cell culture, transfections, and luciferase assays}

MA-10 mouse Leydig tumor cells (Ascoli 1981), a generous gift from Dr Mario Ascoli (Department of Pharmacology, University of Iowa College of Medicine, Iowa City, IA, USA) were maintained in growth medium containing antibiotics (Manna et al. 2002a). HeLa cells were cultured in Dulbecco's modified Eagle's medium (DMEM) supplemented with 10\% fetal bovine serum (FBS; Life Technologies, Inc., Gaithersburg, MD, USA), streptomycin $(50 \mathrm{mg} / \mathrm{l})$ and penicillin $(50000 \mathrm{U} / \mathrm{l})$ at $37^{\circ} \mathrm{C}$ with $5 \% \mathrm{CO}_{2}$. 
Transfection studies were carried out using FuGENE 6-transfection reagent (Roche Diagnostics Corp., Indianapolis, IN, USA) according to the instructions of the manufacturer under optimized conditions (Manna et al. 1999b, 2001). For promoter studies, cells were transfected with CREB-pCR3·1 (wild-type (WT) CREB), GREMpSG5 $(\alpha, \beta$, and $\tau)$, or SF-1-pCMV expression plasmids $(1 \mu \mathrm{g}$ each), or a combination of CREB plus SF-1, in the presence of $1 \mu \mathrm{g} 5$ '-flanking StAR plasmid (-151/-1 StAR/luc). Transfection efficiency was normalized by co-transfecting $10 \mathrm{ng}$ pRL-SV40 vector (a plasmid that constitutively expresses renilla luciferase). Luciferase activity in the cell lysates was determined by the Dualluciferase reporter assay system (Promega Corp., Madison, WI, USA), using a TD 20/20 Luminometer (Turner Designs, Sunnyvale, CA, USA), as described previously (Manna et al. 2002a).

\section{Site-directed mutagenesis and construction of the CRE and SF-1 mutants}

The $-151 /-1 \mathrm{bp}$ region of the mouse StAR promoter was synthesized using a PCR based cloning strategy (Manna et al. 2002a). Briefly, a XhoI and HindIII fragment containing -151/ -1 bp was subcloned into the cloning sites of the pGL3 basic vector (Promega Corp.) which contains the firefly luciferase gene as a reporter. Using the $-151 /-1$ StAR-pGL3 as template, mutations in the CRE half-sites and SF-1 recognition motifs were generated using the Quikchange site-directed mutagenesis kit (Stratagene, La Jolla, CA, USA). The sense strands of the oligonucleotides (corresponding positions in parentheses) used were (mutated (Mut) bases in lower case bold) the following: CRE1 Mut (-113 to $-78 \mathrm{bp}), 5^{\prime}$ GGCAATCATTCGATCGTTccggaTCTGCAC AATGAC-3'; CRE2 Mut (-99 to $-60 \mathrm{bp}), 5^{\prime}$ CGTTGACGCTCTGCACAATagaTctTGACT TTTTTATCTC-3'; CRE3 Mut (-93 to $-60 \mathrm{bp}$ ), 5'-CGCTCTGCACAATGACTGAgatCTTTTT TATCTC-3'; CRE2\&3 Mut (-99 to $-57 \mathrm{bp})$, 5'-CGTTGACGCTCTGCACAAgcggecgcGAC TTTTTTATCTCAAG-3'; SF-1/1 Mut (-153 to -124 bp), 5'-GAGTCTGCTCGCTCgaAttcTGG CGAGCAC-3'; SF-1/2 Mut (-52 to $-30 \mathrm{bp})$, 5'-GATGCACAGCtgTCGACGGGAAG-3'; SF1/3 Mut (-111 to $-84 \mathrm{bp}), 5$-CAATCATTCGA gCtgTGACGCTCTGCAC-3'. All mutations were verified by restriction mapping using Sau3AI (CRE1 Mut), BglII (CRE2 Mut and CRE3 Mut), NotI (CRE2\&3 Mut), EcoRI (SF-1/1 Mut), PvuII (SF-1/2 Mut and SF-1/3 Mut). Mutations in the GRE and SF-1 elements were also generated in combination with appropriate CRE and SF-1 single/double mutation vectors as the PCR template, and re-ligated into the pGL3 vector as a XhoI and HindIII fragment. Assessment of these mutations was confirmed by automated sequencing on a PE Biosystems 310 Genetic Analyzer (ABI PRISM 310, Perkin-Elmer) at the Texas Tech University Biotechnology Core Facility.

\section{Preparation of recombinant CREB protein}

The cDNA encoding CREB protein was cloned into the T7 expression vector pET11d, and recombinant CREB protein was produced in Escherichia coli as described previously (de Groot et al. 1994).

\section{Electrophoretic mobility shift assays (EMSA)}

The nuclear extracts (NE) from cultured MA-10 cells were prepared utilizing previously described procedures (Dignam et al. 1983, Manna et al. 2002a). The oligonucleotide probes were engineered and synthesized by heating sense and antisense primers to $65{ }^{\circ} \mathrm{C}$ for $5 \mathrm{~min}$ in annealing buffer $(10 \mathrm{mM}$ Tris- $\mathrm{HCl}, 100 \mathrm{mM} \mathrm{NaCl}, 1 \mathrm{mM}$ EDTA, pH 7.5), followed by cooling at room temperature. The following sense strands of the oligonucleotide sequences (mutated (Mut) bases in lower case bold) were used: CRE2 (-83/-67 bp), 5'-GGAATGACTGAAGTATTTT-3'; consensus GRE (Con CRE (Montminy et al. 1986)), 5'- GGAGAGATTGGCTGAGGTCAGAGAGG TAG -3'; three CRE half-sites (-96/-67 bp), 5'-GGTGACGGTCTGCACAATGACTGATGA GTTTT-3'; CRE1 Mut, 5'-GGTccggaTGTGCA CAATGACTGATGACTTTT-3'; CRE2 Mut, 5'GGTGACGCTCTGCACAATagaTctTGACTT TT-3'; GRE3 Mut, 5'-GGTGACGCTCTGCAC AATGACTGAgatCTTTT-3'; CRE1,2,3 Mut, 5'-GGTccggaTCTGCACAATagaTctgatCTT TT-3'; SF-1/1 (-142/-128 bp), 5'-GGCTCGCA CCTTGGCCA-3'; SF-1/1 Mut, 5'-GGCTCgaA ttcTGGCGA-3'; SF-1/2 (-48/-35 bp), 5'-GGCA CAGCGTTCGACG-3'; SF-1/2 Mut, 5'-GGC ACAGCtgTCGACG-3'; SF-1/3 (-106/-92 bp), 
5'-GGATTCGATCGTTGACG-3'; SF-1/3 Mut, 5'-GGATTCAAgCtgTGACG-3'; SF-1/3-CRE2 (-103/-74 bp), 5'-GGCGATCGTTGACGCTCT GCACAATGACTGAT-3'; -103/-74 SF-1/3 Mut, 5'-GGCGAgCtgTGACCCTCTGCACAATGAC TGAT-3'; -103/-74 CRE2 Mut, 5'-GGCCA TCGTTGACGCTCTGCACAATagaTctT-3'; SF1/3-CRE2 Mut (-103/-74), 5'-GGCGAgCtgTG AGCGTCTGCACAATagaTct T-3'. The doubled stranded oligonucleotides were end-labeled with $\left[\alpha^{32} \mathrm{P}\right] \mathrm{dCTP}$ (Easytides, $3000 \mathrm{Ci} / \mathrm{mmol}$, PerkinElmer Life Sciences, Inc., Boston, MA, USA) using Klenow (Promega Corp.) fill-in reaction at $25^{\circ} \mathrm{C}$ for $15 \mathrm{~min}$ and purified by spin column (Amersham Pharmacia Biotech, Piscataway, NJ, USA). Protein-DNA binding experiments were carried out under optimized conditions as described previously (Eubank et al. 2001, Manna et al. 2002a). Briefly, NE $(10-20 \mu \mathrm{g})$ and recombinant $(\mathrm{rec})$ CREB protein $(1-6 \mu \mathrm{g})$ were incubated in $15 \mu \mathrm{l}$ reaction buffer $(10 \mathrm{mM}$ HEPES, $1 \mathrm{mM}$ EDTA, 4\% Ficoll, $10 \mathrm{mM}$ dithiothreitol, $1 \mu \mathrm{g}$ poly $\mathrm{dIdC}, 40 \mathrm{ng} / \mu \mathrm{l} \mathrm{BSA}$, and $2 \mu \mathrm{M} \mathrm{ZnSO}_{4}, \mathrm{pH} 7 \cdot 9$ ). $\mathrm{NE}$ was incubated for $15 \mathrm{~min}$ at room temperature prior to the addition of a ${ }^{32}$ P-labeled probe ( $\sim 100000$ c.p.m.) either alone, or in the presence of $50 \mathrm{pM}$ (100-fold molar excess) unlabeled oligonucleotide probe for an additional $15 \mathrm{~min}$. Binding reaction was carried out for $45 \mathrm{~min}$ on ice when SF-1 antibody (rabbit polyclonal antibody directed against full-length SF-1 protein (Morohashi et al. 1993)) was used $(4 \mu \mathrm{g})$, before the addition of the labeled probe. The reaction mixture was then subjected to electrophoresis on 5\% polyacrylamide gels in $0.5 \times \mathrm{TBE}$ buffer $(90 \mathrm{mM}$ Tris-borate, $2 \mathrm{mM}$ EDTA, pH 8·3). The gels were dried, exposed either to phosphor screens or to Hyperfilm (Amersham Pharmacia Biotech) and quantitated using computer-assisted image analysis (Visage 2000, BioImage, Ann Arbor, MI, USA).

\section{Mammalian two-hybrid assay}

The protein-protein interaction between CREB/ CREM $\tau$ and SF-1 was assessed with the mammalian two-hybrid assay, according to the instructions of the manufacturer (Promega Corp.). Briefly, CREB-pACT, CREB-M1-pACT (nonphosphorylatable mutant, Ser ${ }^{133}$ Ala substitution), and CREM $\tau$-pACT plasmids were constructed using WT-CREB, GREB-M1, and CREM $\tau$ cD-
NAs inserted into the SalI and KpnI sites. The full-length mouse SF-1 cDNA was inserted into the BamHI and NotI sites of the pBIND vector. HeLa cells were transfected with CREB-pACT, CREBM1-pACT, CREM $\tau$-pACT, or SF-1-pBIND plasmids ( $2 \mu \mathrm{g}$ each) or their combination, as indicated, in the presence of pG5-luciferase vector, using FuGENE 6 reagent (Roche Diagnostics Corp.). Following $48 \mathrm{~h}$ transfection, cells were harvested and luciferase activity in the cell lysates was determined using a TD 20/20 Luminometer (Turner Designs).

\section{Statistical analysis}

Statistical analysis was performed by analysis of variance (ANOVA) using Statview (Abacus Concepts Inc., Berkeley, CA, USA) followed by Fisher's protected least significant differences test. All experiments were repeated three to four times as indicated in the figure legends. $P<0.05$ was considered statistically significant.

\section{Results}

\section{Role of CREB and CREM on StAR gene transcription}

The role of CREB in the regulation of steroid biosynthesis and StAR protein expression has recently been demonstrated in steroidogenic cells, where the endogenous factor was determined to be predominantly the CREM protein (Manna et al. 2002a). Also, 5'-deletion analyses demonstrated the presence of a CREB/CREM responsive region(s) within the $-110 /-1 \mathrm{bp}$ of the mouse StAR gene, the region found to be associated with a decrease in cAMP-stimulated StAR reporter activity in the absence of CREB/CREM. Thus, a relatively longer fragment $(-151 /-1 \mathrm{bp})$ was used in the present studies to investigate the regulatory mechanism involved in StAR gene transcription by the cAMP pathway. As illustrated in Fig. 1, MA-10 cells transfected with the $-151 /-1$ bp StAR promoter fragment $(-151$ StAR) demonstrated a 3.9-fold increase in luciferase activity following $6 \mathrm{~h}$ of $(\mathrm{Bu})_{2} \mathrm{cAMP}(500 \mu \mathrm{M})$ stimulation. However, over-expression of WT-CREB (CREB) or GREM $\tau$ in the presence of the -151 StAR segment demonstrated a further $3 \cdot 7$-fold increase in promoter activity by cAMP when compared with 


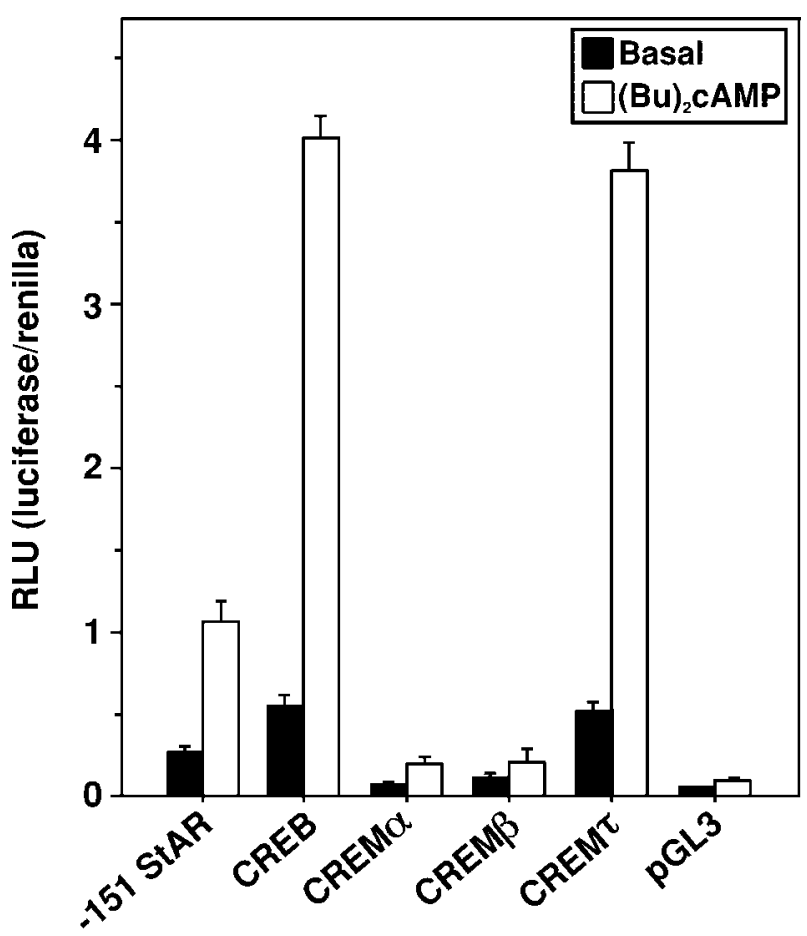

Figure 1 Over-expression of CREB and CREM on StAR promoter activity in MA-10 cells. Cells were transiently transfected with the $-151 /-1$ bp StAR reporter plasmid (-151 StAR), without or with WT-CREB (CREB), CREM $\alpha, C R E M \beta$, and CREM $\tau$ ( $2 \mu \mathrm{g}$ each) in the presence of $\mathrm{pRL}-\mathrm{SV} 40$, using FuGENE 6 -transfection reagent as described under Materials and methods. Thirty-six hours after transfection, cells were stimulated without (Basal) or with $(\mathrm{Bu})_{2} \mathrm{cAMP}(500 \mu \mathrm{M})$ for 6 h. pGL3-basic (pGL3) was used as a control. Luciferase activity in the cell lysates was determined and expressed as relative light units, RLU (luciferase/renilla). Data represent the means \pm S.E.M. of three independent experiments.

control (-151 StAR), and the magnitude of response was qualitatively similar in both cases. In contrast, cells expressing CREM $\alpha$ or CREM $\beta$ markedly decreased basal and $(\mathrm{Bu})_{2} \mathrm{cAMP}-$ stimulated promoter responses when compared with controls. CREB and CREM $\tau$ also significantly increased $(P<0.05)$ basal promoter activity. CREB was used to assess the transcriptional regulation of the StAR gene in subsequent experiments.

\section{Assessment of CRE half-sites in CREB responsiveness}

Recently, we identified three canonical GRE half-sites (GRE1, GRE2 and CRE3) within the
-96/-67 bp of the mouse StAR gene (Manna et al. $2002 a$ ). It was also observed that an oligonucleotide probe (-96/-67) containing these CRE half-sites demonstrated formation of three protein-DNA complexes (I, II, and III) with MA-10 nuclear extracts (NE), which were affected by the CRE mutants in EMSA. In the present findings, direct involvement of these CRE elements was assessed by generating mutations in each of the CRE half-sites using EMSA (Fig. 2). Using (Bu) ${ }_{2}$ CAMP-stimulated MA-10 NE, the occurrence of protein-DNA binding observed with the CRE1 mutant (lanes 1 to 3) was clearly decreased with a probe containing mutation in the CRE3 site (lanes 9 to 11). On the other hand, protein-DNA complexes were greatly diminished with the CRE2 mutant probe (lanes 5-7). Protein-DNA complexes observed with the different GRE elements were further competed with their cold competitors or with a consensus CRE sequence (Con CRE). Mutations introduced in the three CRE half-sites together markedly affected protein-DNA binding (lanes 13-15). The importance of these CRE elements on StAR promoter function using the -151 StAR segment was also studied. MA-10 cells transfected with the CRE1 (TGACGCTC to TccggaTC), CRE2 (TGACTGAT to TagaTctT), and CRE3 (TGACTTTT to gatCTTTT) mutants demonstrated approximately 33, 47 and 18\% decreases in basal luciferase response without affecting $(\mathrm{Bu})_{2} \mathrm{cAMP}-m e d i a t e d$ fold-induction when compared with the -151 StAR, an observation in agreement with the previous findings (Manna et al. 2002a). Also, mutations in the double and/or triple GRE sites demonstrated further decreases in StAR promoter activity (data not shown). These observations demonstrate the relative involvement of the three CRE half-sites in StAR gene expression.

The functional involvement of these CRE half-sites in response to GREB was then studied in MA-10 cells. Cells transfected with the -151 StAR segment demonstrated a $4 \cdot 2$-fold increase in $(\mathrm{Bu})_{2} \mathrm{CAMP}$-stimulated reporter activity. Transfection of CREB in the presence of the -151 StAR segment showed a further $3 \cdot 5$-fold increase in luciferase activity by $(\mathrm{Bu})_{2} \mathrm{cAMP}$ when compared with the -151 StAR (Fig. 3). However, in the presence of a CRE2 mutant, CREB expression resulted in a 58\% decrease in basal and $(\mathrm{Bu})_{2} \mathrm{cAMP}$-stimulated luciferase responses when compared with controls. When expressed along 


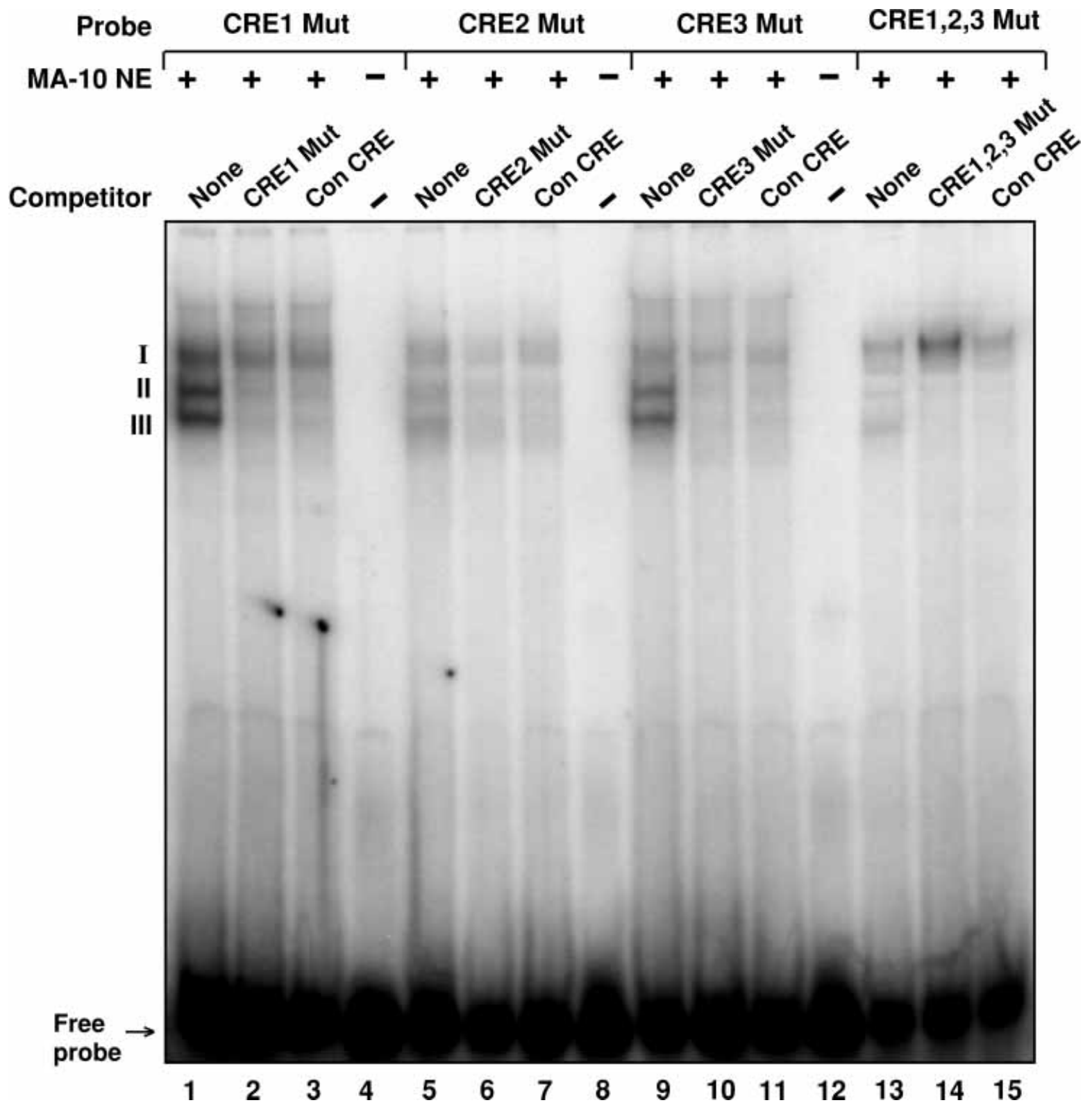

Figure 2 Binding of the different CRE mutants to MA-10 nuclear extract (NE). MA-10 cells were stimulated for $6 \mathrm{~h}$ with $(\mathrm{Bu})_{2} \mathrm{CAMP}(500 \mu \mathrm{M})$, and $10 \mu \mathrm{g} \mathrm{NE}$ were assessed in EMSA to analyze protein-DNA binding using the ${ }^{32} \mathrm{P}$-labeled CRE elements $(-96 /-67 \mathrm{bp})$ containing mutations, as described in Materials and methods. Cold competitors were used at 100 -fold molar excess. Protein-DNA complexes were resolved on a $5 \%$ polyacrylamide gel for about $1.5 \mathrm{~h}$ at $200 \mathrm{~V}$, the gels were dried, and the complexes were visualized by a phosphorimaging device. A representative phosphorimage illustrates formation of protein-DNA complexes to the labeled CRE1 (lanes 1-4), CRE2 (lanes 5-8), CRE3 (lanes 9-12), and CRE1,2,3 (lanes 13-15) mutant probes. Protein-DNA complexes are marked as I, II, and III. The experiments were repeated three times. Free probes are shown in each lane. Con CRE, consensus CRE sequence.

with mutant GRE1 and CRE3 sites, CREB expression resulted in decreases in $(\mathrm{Bu})_{2} \mathrm{CAMP}-$ stimulated StAR promoter activities by 23 and $30 \%$ respectively, demonstrating that the CRE2 plays the most important role in CREB responsiveness. Notably, the $(\mathrm{Bu})_{2} \mathrm{cAMP}-$ mediated 


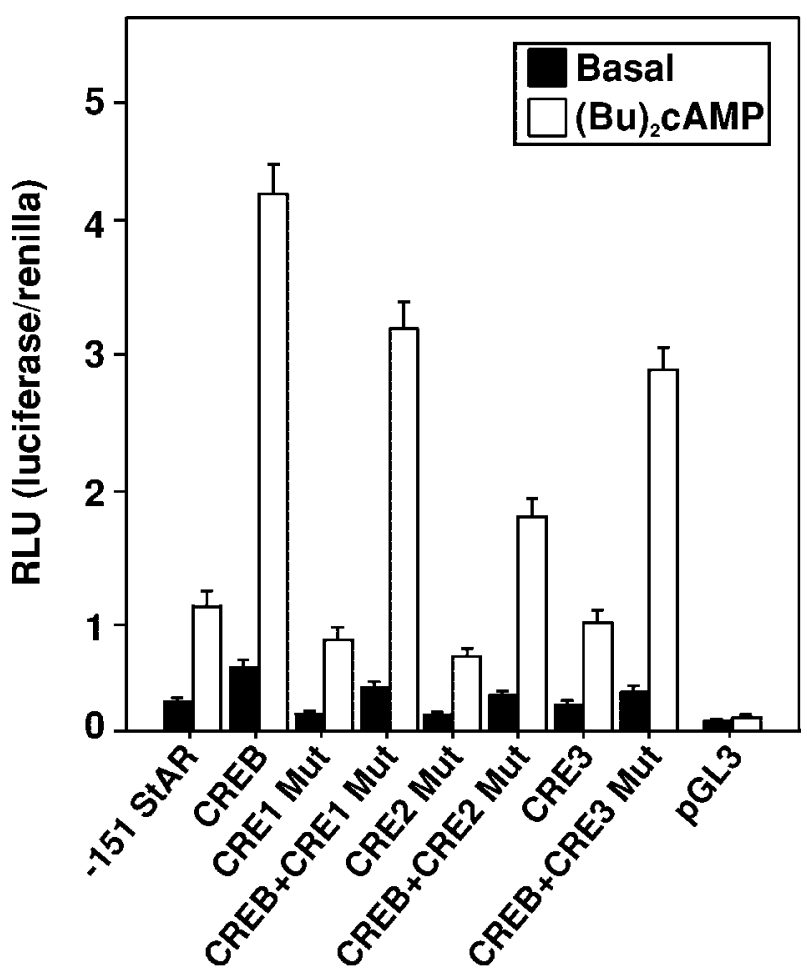

Figure 3 Influence of CRE half-sites on CREBresponsive StAR promoter activity. MA-10 cells were transfected with either the $-151 /-1$ bp StAR segment (-151 StAR), or the -151 StAR containing mutations in each of the CRE half-sites, without or with WT-CREB (CREB), in the presence of pRL-SV40. Following $36 \mathrm{~h}$ of transfection, cells were incubated for a further $6 \mathrm{~h}$ in the absence (Basal) or presence of $(\mathrm{Bu})_{2} \mathrm{cAMP}$ $(500 \mu \mathrm{M})$. pGL3-basic (pGL3) was used as a control. Luciferase activity in the cell lysates was determined and expressed as relative light units, RLU (luciferase/renilla). These experiments were repeated four times, and values are the means \pm S.E. of an experiment carried out in triplicate.

fold-induction was not affected by the CRE/CREB system in spite of decreases in basal reporter activities.

In order to determine further the importance of the CRE2 site, a wild-type CRE2 probe (-83/ $-67 \mathrm{bp})$ was utilized in EMSA demonstrating rec CREB protein binding. As shown in Fig. 4A, the CRE2 probe demonstrated a concentrationdependent increase in the formation of a specific protein-DNA complex (complex I) with rec CREB protein (lanes 1-3). Protein-DNA binding was strongly inhibited by cold CRE2 (lane 4) and Con CRE (lane 5) sequences. As illustrated in Fig. 4B, the CRE2 probe can also bind to MA-10 NE in a
$(\mathrm{Bu})_{2}$ cAMP-responsive manner (compare lanes 2 and 3), forming three protein-DNA complexes (I, II, and III). However, protein-DNA binding at complex I was nearly abolished with this probe, suggesting that GRE1 and CRE3 may have roles to play. Protein-DNA complexes were markedly decreased with cold competitors, including its unlabeled sequence (lane 4), Con CRE (lane 5), and with the $-96 /-67$ bp (a region containing three CRE half-sites, lane 6) sequences. These data further indicate the critical involvement of CRE2 on CREB responsiveness.

\section{CREB and SF-1 mediate maximal StAR promoter response}

The cAMP and CREB/CREM responsive regions $(-151 /-1)$ of the mouse StAR gene have been shown to contain three SF-1 binding motifs which are instrumental in StAR gene expression (Caron et al. 1997, Wooton-Kee \& Clark 2000, Manna et al. 2002b). We next studied whether CREB and $\mathrm{SF}-1$ play roles in StAR gene transcription. MA-10 cells transfected with the $-151 /-1 \mathrm{bp}$ StAR segment (-151 StAR) demonstrated a significant increase $(P<0.01)$ in $(\mathrm{Bu})_{2}$ cAMP-stimulated reporter activity over untreated cells. Overexpression of either WT-CREB (CREB) or SF-1 displayed approximately $3 \cdot 7$ - or 2 -fold increases in $(\mathrm{Bu})_{2} \mathrm{cAMP}-$ mediated StAR promoter activities respectively, when compared with the -151 StAR (Fig. 5). However, co-expression of CREB and $\mathrm{SF}-1$ resulted in a $5 \cdot 2$-fold increase in $(\mathrm{Bu})_{2} \mathrm{cAMP}$ stimulated StAR promoter activity, demonstrating that CREB and SF-1 activate StAR promoter activity in an additive fashion.

The relative importance of different SF-1 recognition sites on StAR promoter activity was studied by mutational analysis utilizing the -151 StAR segment. When MA-10 cells were transfected with the -151 StAR/luciferase construct, the $(\mathrm{Bu})_{2} \mathrm{cAMP}$-stimulated luciferase activity increased significantly $(P<0.01)$ over untreated cells (Fig. 6). Mutation in the $\mathrm{SF}-1 / 1$ site (CACGTT to aAttcT) showed a $42 \%$ decrease in basal luciferase response, but did not affect StAR promoter activity induced by $(\mathrm{Bu})_{2} \mathrm{CAMP}$. The SF-1/2 mutant (CAGCGTT to CAGCtgT), on the other hand, demonstrated a modest decrease $(\sim 20 \%)$ in reporter activity without affecting $(\mathrm{Bu})_{2} \mathrm{cAMP}-$ mediated fold activity. An approximately 54\% 
decrease in basal and $(\mathrm{Bu})_{2} \mathrm{cAMP}-$ mediated reporter activities was observed with the $\mathrm{SF}-1 / 3$ mutant (CATCGTT to CAgCtgT). It is interesting to note that a different mutation in the SF-1/3 site (CATCGTT/g) that also involves the CRE1 site was found to decrease StAR promoter activity by
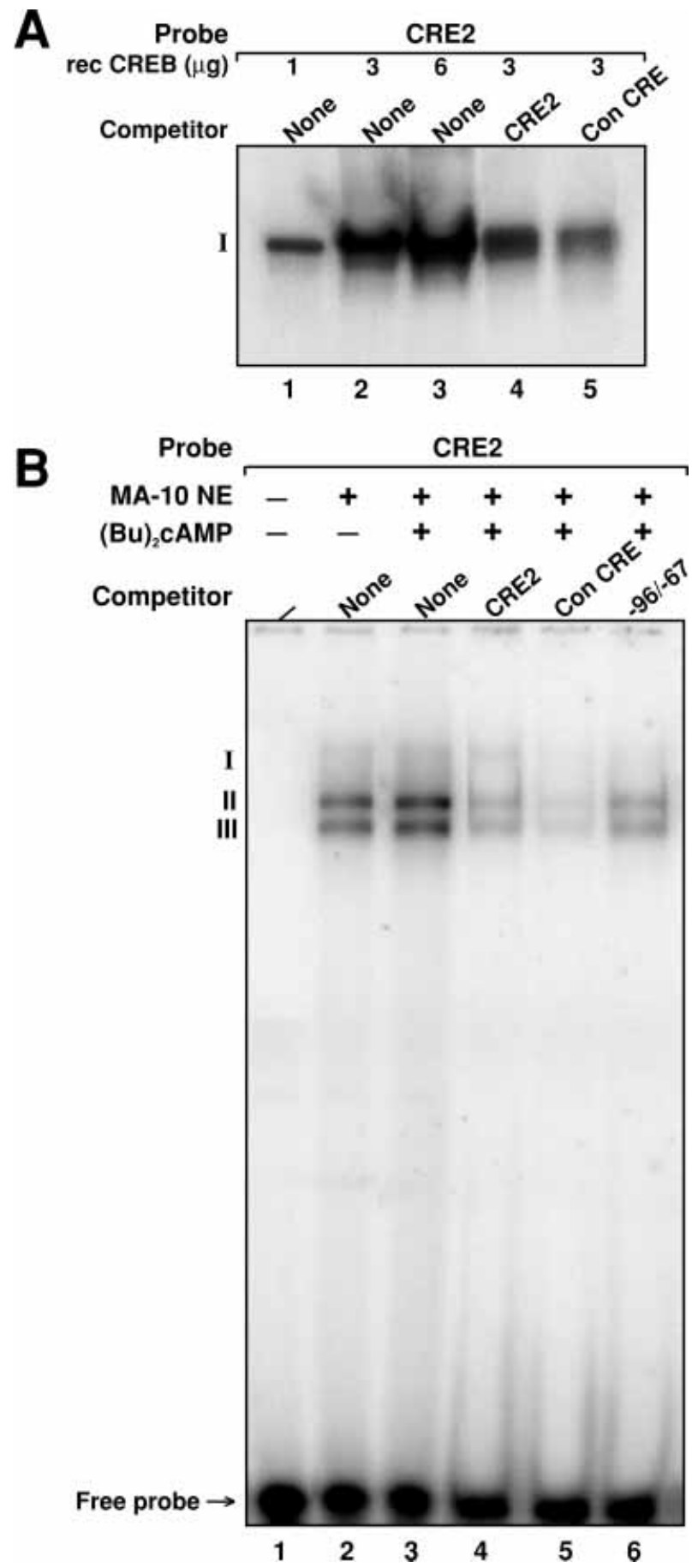

80\% (Manna et al. 2002a). Mutations carried out with double SF-1 recognition motifs, in any combination, further decreased reporter activity. These data suggest an important involvement of the $\mathrm{SF}-1 / 3$ in StAR promoter activity in comparison with the SF-1/1 and SF-1/2 sites.

The involvement of different SF-1 binding motifs in StAR gene expression was further investigated in protein-DNA binding using EMSA. As shown in Fig. 7, oligonucleotide probes consisting of different SF-1 elements (SF-1/1, SF-1/2, and SF-1/3) demonstrated a specific protein-DNA complex with nuclear proteins isolated from $(\mathrm{Bu})_{2} \mathrm{cAMP}-$ stimulated MA-10 cells (lanes 1-12). It can be seen that formation of the protein-DNA complex was relatively higher with the SF-1/3 (lanes 9-12) in comparison with the SF-1/1 (lanes 1-4) and SF-1/2 (lanes 5-8) probes. In all cases, proteinDNA binding was decreased following addition of different unlabeled SF-1 probes or SF-1 antibody. On the other hand, similar mutations (as above) generated in different SF-1 core sequences did not affect the protein-DNA complex. These data demonstrate the relative involvement of the three SF-1 elements in MA-10 nuclear protein-DNA binding where the $\mathrm{SF}-1 / 3$ site plays the most important role.

To assess the relationship between GRE2 and SF-1 elements, StAR promoter activity was studied utilizing the -151 StAR promoter fragment containing the CRE2 mutant in combination with

Figure 4 Binding of the CRE2 sequence to recombinant (rec) CREB protein and MA-10 NE in EMSA. (A) Increasing amounts of rec CREB protein $(1-6 \mu \mathrm{g})$ was used for binding with a ${ }^{32}$ P-labeled CRE2 (-83/-67 bp) probe (lanes 1-5). Protein-DNA reactions were performed as described in Materials and methods, and in the legend to Fig. 2. A representative autoradiogram shows rec CREB protein binding to the labeled CRE2 DNA. Cold competitors (CRE2, lane 4 and Con CRE, lane 5) were used at 100 -fold molar excess. Formation of a specific protein-DNA complex is marked as I. (B) Binding of the CRE2 probe to MA-10 NE in EMSA. NE $(10 \mu \mathrm{g})$ was used from control (lane 2) and $(\mathrm{Bu})_{2} \mathrm{CAMP}$ (500 $\mu \mathrm{M} ; 6$ h)-stimulated MA-10 cells (lanes 3-6). Formation of protein-DNA complexes is marked as I, II and III. Cold competitors (CRE2, lane 4, Con CRE, lane 5 and $-96 /-67$ bp containing three CRE half-sites, lane 6 ) were used at 100 -fold molar excess. These experiments were repeated 3-4 times, and a representative phosphorimage experiment is illustrated. Con CRE, consensus CRE sequence. 


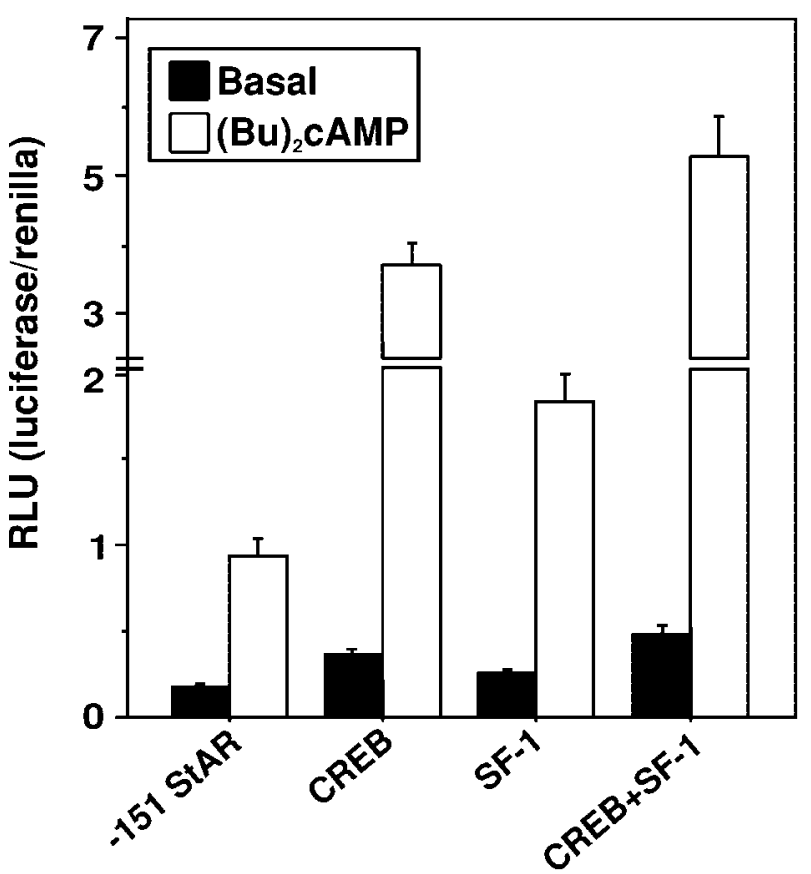

Figure 5 Over-expression of CREB and SF-1 on StAR promoter activity. MA-10 cells were transfected with the $-151 /-1$ bp StAR segment (-151 StAR), without or with WT-CREB (CREB), SF-1 (2 $\mu$ g each), or a combination of them in the presence of pRL-SV40. Thirty-six hours after transfection, cells were stimulated for a further $6 \mathrm{~h}$ in the absence (Basal) or presence of $(\mathrm{Bu})_{2} \mathrm{CAMP}$ $(500 \mu \mathrm{M})$. Luciferase activity was determined in the cell lysates and expressed as relative light units, RLU (luciferase/renilla). Values represent the means \pm S.E.M. of four independent experiments.

different SF-1 mutants. Transfection with the CRE2 mutant demonstrated a significant decrease $(P<0.05)$ in StAR promoter activity following $(\mathrm{Bu})_{2} \mathrm{CAMP}$ stimulation (Fig. 8). The CRE2 mutant in the presence of the SF-1/3 mutant resulted in an $85 \%$ decrease in basal promoter activity, without affecting $(\mathrm{Bu})_{2} \mathrm{cAMP}-$ mediated foldresponse. Moreover, mutation in the CRE2 site in combination with the $\mathrm{SF}-1 / 1$ or $\mathrm{SF}-1 / 2$ mutants decreased $(\mathrm{Bu})_{2} \mathrm{cAMP}$-stimulated luciferase responses by 60 and $47 \%$ respectively, when compared with the -151 StAR. It was also observed that transfection of CREB and SF-1 in the presence of either CRE2 or SF-1/3 mutants within the context of $-151 \mathrm{StAR}$ segment resulted in marked decreases in basal and $(\mathrm{Bu})_{2} \mathrm{cAMP}-$ mediated reporter activities (data not shown). In fact, mutations in the CRE2 and SF-1 binding sites

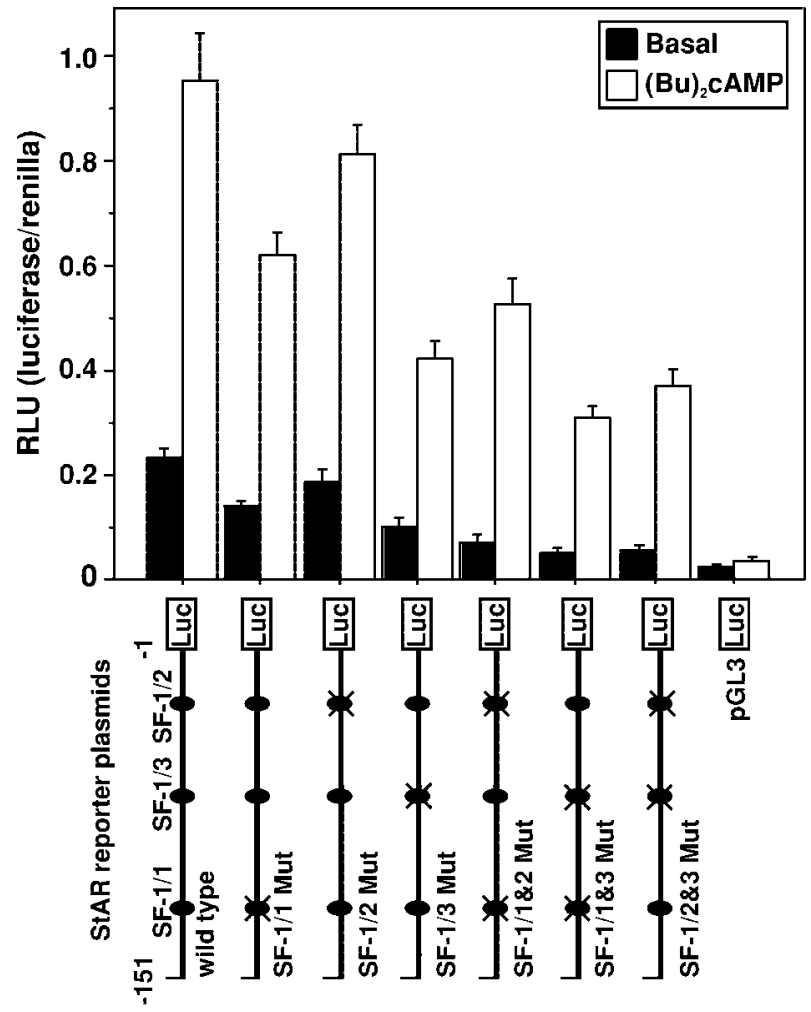

Figure 6 Assessment of different SF-1 binding sites on StAR promoter function. MA-10 cells were transfected with either the $-151 /-1$ bp StAR reporter plasmid $(-151$ StAR) or the -151 StAR containing mutations in one or more SF-1 binding sites, in the presence of pRL-SV40. Following $36 \mathrm{~h}$ of transfection, cells were stimulated for a further $6 \mathrm{~h}$ without (Basal) or with $500 \mu \mathrm{M}(\mathrm{Bu})_{2} \mathrm{CAMP}$. pGL3-basic (pGL3) was used as a control. Luciferase activity in the cell lysates was determined and expressed as relative light units, RLU (luciferase/ renilla). Bottom panel shows schematic presentation of different SF-1 binding sites together with the mutations within the $-151 /-1$ bp StAR segment. These experiments were repeated 3-4 times, and values are the means \pm S.E. of an experiment carried out in triplicate.

demonstrated cooperation of these elements in stimulation of the StAR promoter.

To obtain more insight into these mechanisms, an oligonucleotide probe corresponding to the SF-1/3-CRE2 region (-103/-74) was studied in EMSA using $\mathrm{NE}$ obtained from $(\mathrm{Bu})_{2} \mathrm{cAMP}-$ stimulated MA-10 cells (Fig. 9). However, it is also necessary to take into account that this probe possesses the CRE1 site. Protein-DNA binding observed with the $-103 /-74$ probe was strongly displaced by an excess of its unlabeled sequences 


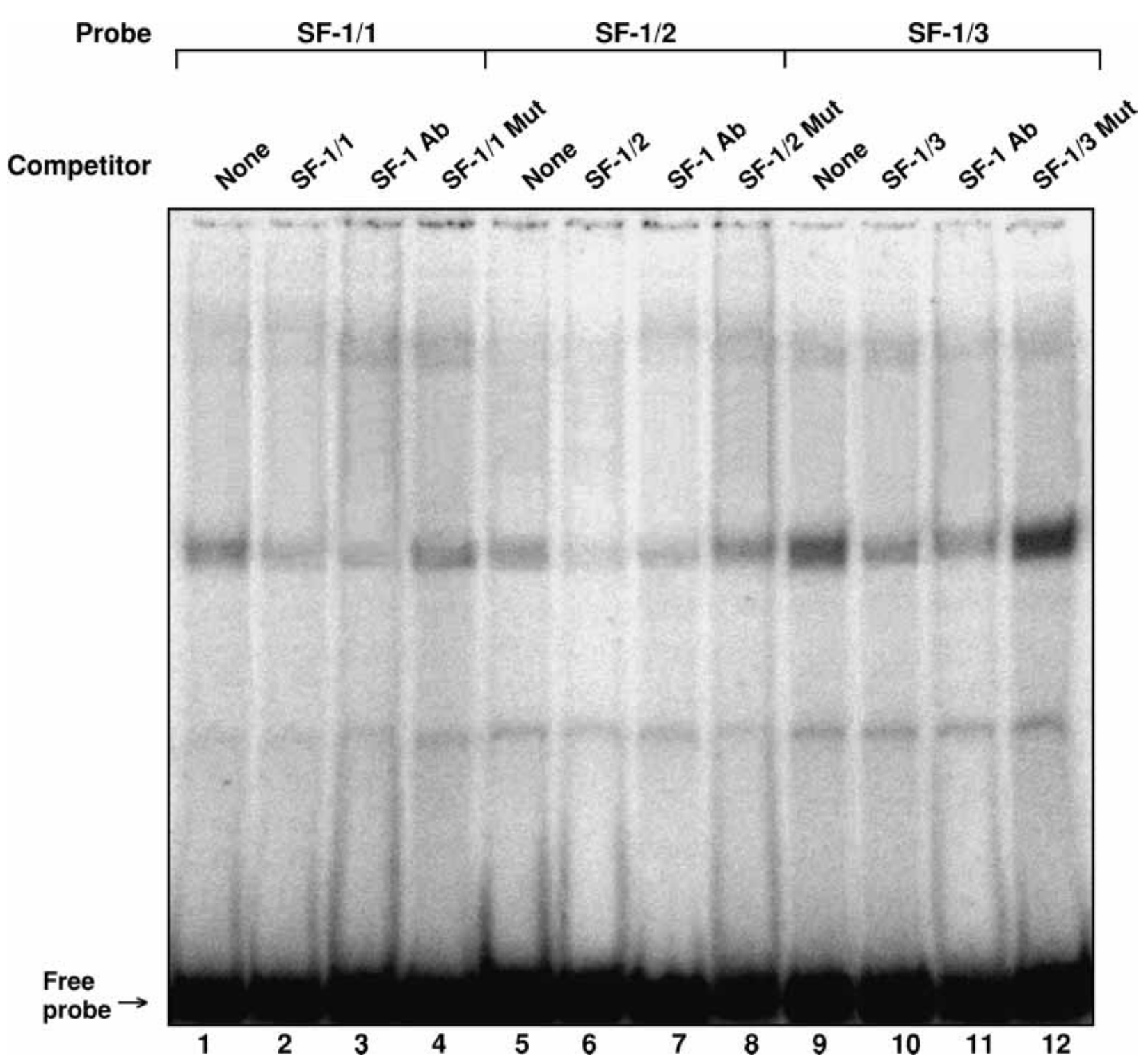

Figure 7 Relative importance of three SF-1 sites on protein-DNA binding using EMSA. NE $(10 \mu \mathrm{g})$ from $(\mathrm{Bu})_{2} \mathrm{CAMP}$ $(500 \mu \mathrm{M}, 6 \mathrm{~h})$-stimulated MA-10 cells was assessed in binding with the ${ }^{32} \mathrm{P}$-labeled SF-1/1 (-142/-128 bp), SF-1/2 (-48/-35 bp), and SF-1/3 (-106/-92 bp) probes, as described in Materials and methods and in the legend to Fig. 2. A representative phosphorimage illustrates formation of a specific protein-DNA complex with the SF-1/1 (lanes 1-4), SF-1/2 (lanes 5-8), and SF-1/3 (lanes 9-12) probes. Cold competitors were used at 100-fold molar excess. Antibody interference analysis was carried out with $4 \mu \mathrm{g}$ polyclonal SF-1 antibody (SF-1 Ab). The experiments were repeated three times. Free probes are shown in each lane.

(compare lane 1 and 2). Mutations (as above) introduced into the $\mathrm{SF}-1 / 3$ or CRE2 sites individually, within the context of the $-103 /-74$ probe, showed a competition with protein-DNA complexes (lanes 3 and 4 respectively), suggesting the involvement of a non-mutated site. However, the SF-1 antibody (lane 6) and Con CRE (lane 7) also decreased protein-DNA complexes. Formation of protein-DNA complexes was not affected with a cold competitor containing mutations in the CRE2 and SF-1/3 binding sites together (lane 5). These data further demonstrate a functional cooperation between CRE2 and SF-1/3 elements in StAR gene expression. 


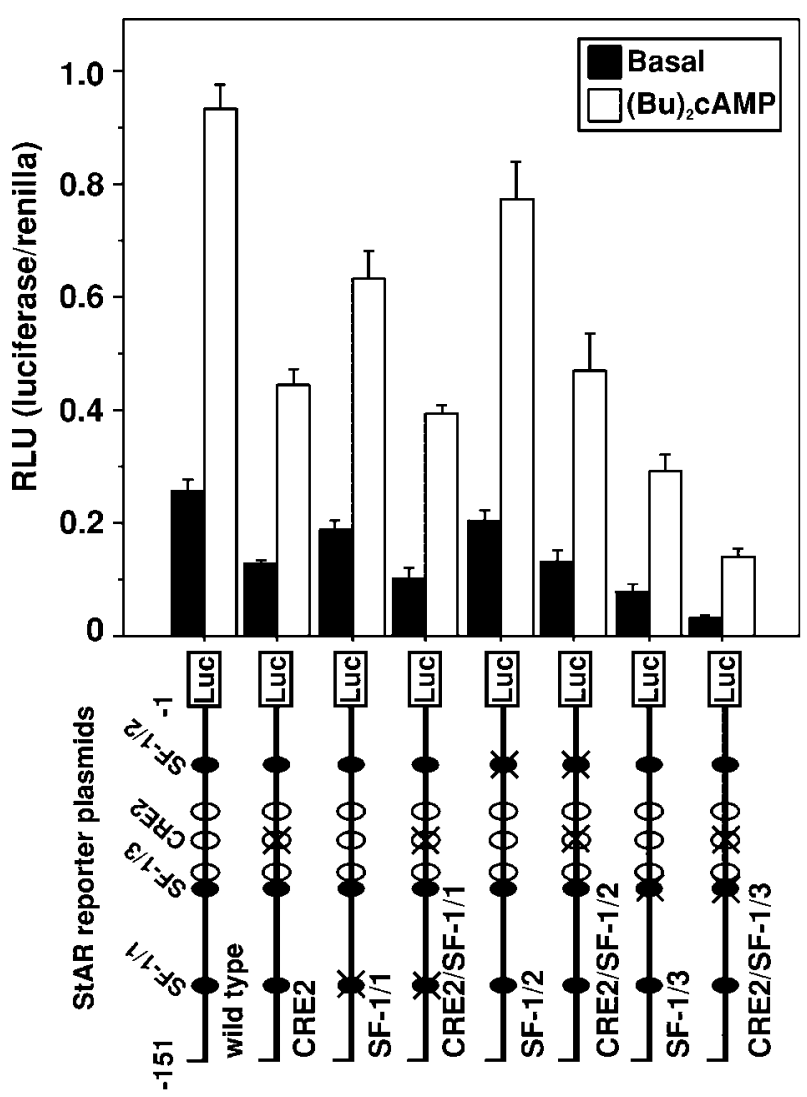

Figure 8 Functional cooperation of CRE2 and SF-1 binding sites on StAR promoter response. MA-10 cells were transfected with either the $-151 /-1$ StAR plasmid $(-151$ StAR) or the -151 StAR containing mutations in the CRE2 and SF-1 elements (as indicated), in the presence of $\mathrm{pRL}-\mathrm{SV} 40$. Thirty-six hours after transfection, cells were incubated for a further $6 \mathrm{~h}$ without (Basal) or with $500 \mu \mathrm{M}(\mathrm{Bu})_{2} \mathrm{CAMP}$, and luciferase activity in the cell lysates was determined and expressed as relative light units, RLU (luciferase/ renilla). Schematic presentation of the CRE2 and SF-1 elements along with their mutations within the $-151 /-1$ bp StAR segment is illustrated in the bottom panel. These experiments were repeated three times, and values are the means \pm S.E. of an experiment carried out in triplicate.

\section{Interaction of CREB and SF-1 in the two-hybrid assay}

The protein-protein interaction between CREB/ CREM $\tau$ and SF-1 was assessed using the mammalian two-hybrid assay system. HeLa cells transfected for $48 \mathrm{~h}$ with CREB-pACT, CREM $\tau$ pACT, and SF-1-pBIND plasmids demonstrated limited effects on luciferase activity (Fig. 10). On the other hand, cells transfected with a non- phosphorylatable mutant $\left(\mathrm{Ser}^{133} \mathrm{Ala}\right)$ of $\mathrm{CREB}$ (CREB-M1-pACT) resulted in a significant decrease $(P<0.05)$ in luciferase response as compared with GREB-pACT. Co-expression of either CREB-pACT or CREM $\tau$-pACT with SF-1-pBIND demonstrated increases in luciferase activity, to levels 4.7-, 16-, and 4-fold higher than those observed with CREB-pACT, SF-1-pBIND, and CREM $\tau$-pACT alone, respectively, suggesting an interaction between CREB/CREM $\tau$ and SF-1. Notably, co-transfection of both CREB-M1pACT and SF-1-pBIND decreased luciferase activity by approximately $60 \%$ when compared with CREB-pACT and SF-1-pBIND expression together, demonstrating the importance of GREB phosphorylation on their interaction (Fig. 10). These data suggest that CREB/CREM $\tau$ and SF-1 are either capable of a direct association or interact through a common adapter protein in vivo.

\section{Discussion}

The combined action of multiple factors have been demonstrated to be involved in the expression and regulation of many genes involved in steroidogenesis (Roesler et al. 1995, Zhang \& Mellon 1996, Carlone \& Richards 1997, Liu \& Simpson 1997, Monte et al. 1998). The product of one of these genes, the StAR protein, plays a critical role in steroid hormone biosynthesis by mediating intramitochondrial cholesterol transport, a process that is regulated by the cAMP pathway. In common with many cAMP-regulated steroidogenic genes, the StAR gene lacks a consensus CRE, suggesting the existence of alternative regulatory factor(s) in cAMP responsiveness. An increasing body of evidence suggests that the involvement of the nuclear receptor SF-1 is common to these pathways. Transcriptional activation of the StAR gene has also been demonstrated by multiple transcription factors including SF-1; however, the mechanism of this regulation is still not clearly understood. While it lacks a consensus CRE, three CRE half-sites located in the proximal region of the mouse StAR gene have recently been identified and the involvement of a CREB/CREM family member in StAR gene expression was demonstrated (Manna et al. 2002a). The present studies extend these observations by demonstrating that 


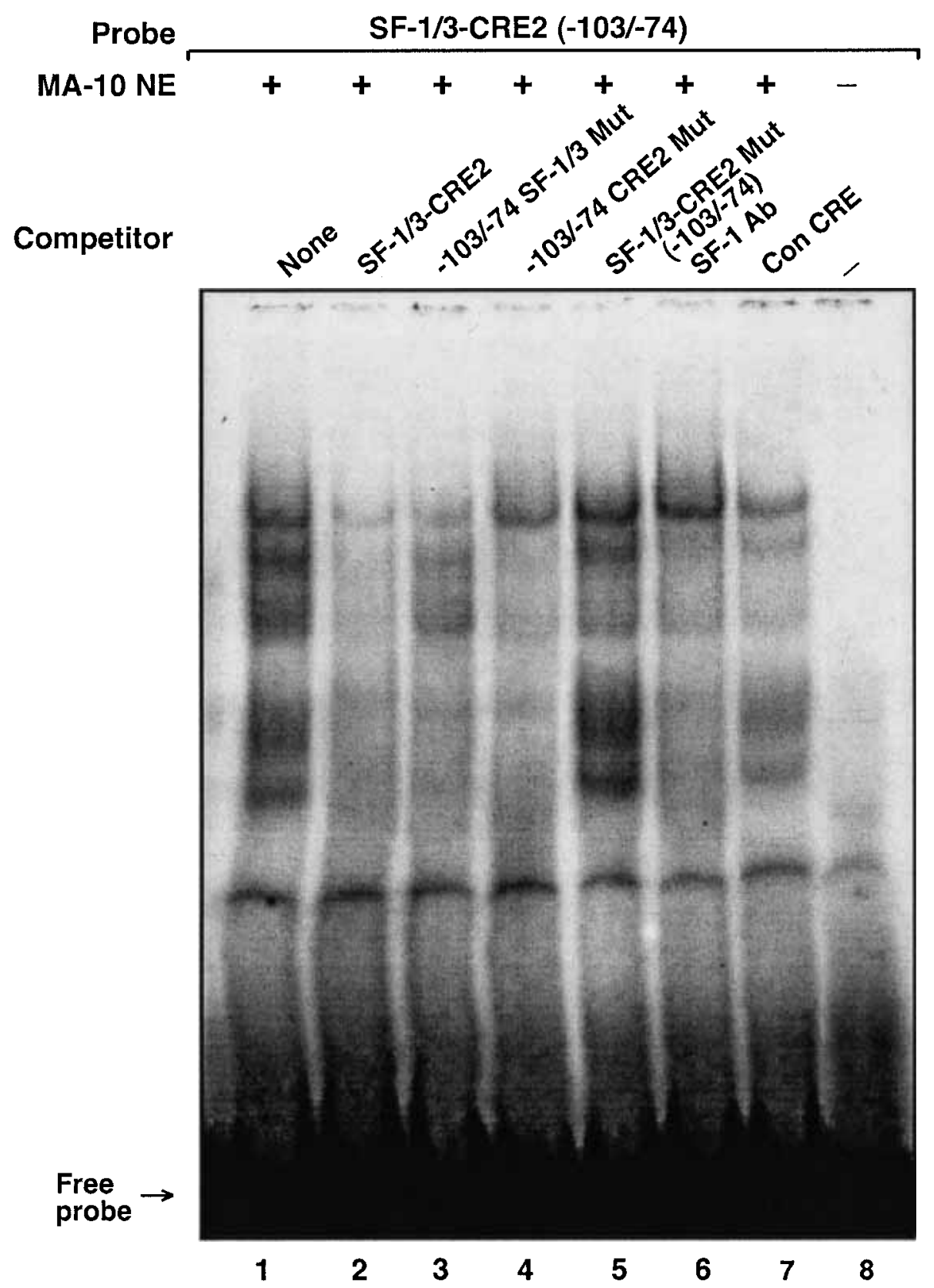

Figure 9 Binding of the SF-1/3-CRE2 region to MA-10 NE in EMSA. $(\mathrm{Bu})_{2} \mathrm{CAMP}$ $(500 \mu \mathrm{M}, 6 \mathrm{~h})$-stimulated MA-10 NE $(10 \mu \mathrm{g})$ was used in binding with the ${ }^{32} \mathrm{P}$-labeled SF-1/3-CRE2 probe (-103/-74 bp), as described in Materials and methods and in the legend to Fig. 2. A representative autoradiogram shows formation of protein-DNA complexes. The following unlabeled competitors were used at 100-fold molar excess: SF-1/3-CRE2 (lane 2), -103/-74 containing mutations in SF-1/3 (-103/-74 SF-1/3 Mut, lane 3), CRE2 (-103/-74 CRE2 Mut, lane 4), or double sites (SF-1/3-CRE2 Mut (-103/-74), lane 5). Protein-DNA binding was also assessed with $4 \mu \mathrm{g}$ polyclonal SF-1 antibody (SF-1 Ab, lane 6) and 100-fold molar excess of consensus CRE (Con CRE, lane 7). The experiments were repeated three times. Free probes are shown in each lane. 


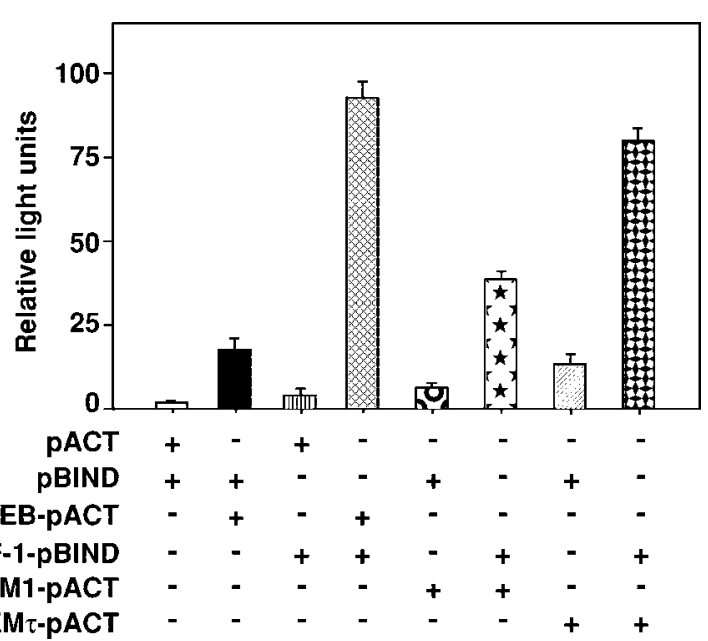

Figure 10 Interaction between CREB/CREM $\tau$ and SF-1 in the mammalian two-hybrid assay. HeLa cells were transfected with CREB-pACT, CREM $\tau$-pACT, CREB-M1-pACT, or SF-1-pBIND (2 $\mu$ g each), or a combination of them as indicated, in the presence of the pG5-luciferase vector, as described in Materials and methods. Following $48 \mathrm{~h}$ of transfection, cells were harvested and luciferase activity in the cell lysates was determined (relative light units). Data represent the means \pm S.E.M. of 3-4 independent experiments.

CREB/CREM $\tau$ and SF-1 interact and cooperate to regulate $\mathrm{StAR}$ gene transcription.

The CREB/CREM/ATF family of transcription factors are distinguishable by their DNA-binding bZIP domains, share many properties, and are involved in cAMP signaling (Dwarki et al. 1990, Gonzalez et al. 1991, Meyer \& Habener 1993, Della Fazia et al. 1997). We recently demonstrated that CREB is capable of increasing cAMPmediated steroid production and StAR expression in steroidogenic cells; however, the predominant endogenous factor was determined to be the CREM protein as assessed by EMSA and RT-PCR analyses (Manna et al. 2002a). Earlier studies have demonstrated that CREM transcripts are higher in the testis than those of CREB and specifically encode the activator form CREM $\tau$ (Delmas et al. 1993, Sassone-Corsi 1995). It has been demonstrated that through alternative splicing the CREM gene can give rise to several isoforms which act as activators $(\tau, \tau 1$, and $\tau 2)$ or repressors $(\alpha, \beta$, and $\gamma)$ of transcription (Lee \& Masson 1993, SassoneCorsi 1995). However, it is noteworthy that functional regions in the CREB protein are identical to GREM $\tau$ (Lee \& Masson 1993). In addition, it was presently observed that overexpression of CREB and CREM $\tau$ resulted in qualitatively similar responses in activation of basal and $(\mathrm{Bu})_{2} \mathrm{cAMP}$-stimulated StAR promoter activities, and these responses were markedly decreased by CREM $\alpha$ and CREM $\beta$ in MA-10 cells, an observation in general agreement with previous findings (Foulkes et al. 1992, Lee \& Masson 1993, Sassone-Corsi 1995).

The identification of three CRE half-sites presented the opportunity to characterize the role of these sites on CREB function that might be involved in the acute regulation of StAR gene (Manna et al. 2002a). Our current findings clearly demonstrate the greater importance of the CRE2 site, as compared with the GRE1 and CRE3 sites, in CREB-mediated StAR gene transcription. Studies have shown that GREB's activation of a promoter can include the binding of multiple CRE binding factors to several CREs rather than the binding of a single set of heterodimers (Fisch et al. 1989, Liu et al. 1991). In the case of the phosphoenol-pyruvate carboxykinase gene promoter it has been shown that several CREs bind to multiple molecules of CREB and exhibit a response to cAMP in a synergistic fashion (Roesler et al. 1995). The integrity of sequence-specific binding of the GRE2 DNA was also investigated with recombinant CREB protein and MA-10 NE using EMSA, where consensus CRE or $-96 /-67 \mathrm{bp}$ (three GRE half-sites) sequences markedly decreased protein-DNA binding. The CRE2 site is also analogous to an activator protein 1 (AP-1) sequence (TGACTGA) and, as such, a role for AP-1 in StAR gene expression cannot be eliminated. Indeed, the AP-1 family, composed of Jun and Fos oncoproteins, was found to be involved in decreasing cAMP mediated StAR gene expression in MA-10 cells (PR Manna, DW Eubank and DM Stocco unpublished data), an observation consistent with recent findings (Manna et al. 2002b, Shea-Eaton et al. 2002).

$\mathrm{SF}-1$ is known to play a key role in adrenal and gonadal differentiation, development and function at multiple levels, including the expression of steroidogenic genes (Ikeda et al. 1994, Ingraham et al. 1994, Parker \& Schimmer 1997). Overexpression of SF-1 has been demonstrated to activate StAR gene expression in steroidogenic and non-steroidogenic cells (Sugawara et al. 1996, Manna et al. 1999a, Reinhart et al. 1999). The 
5 -flanking nucleotide sequences $(-151 /-1)$ of the mouse StAR gene also revealed the presence of three SF-1 binding sites at $-135,-95$, and $-45 \mathrm{bp}$ positions (Caron et al. 1997, Wooton-Kee \& Clark 2000, Manna et al. 2002b). Our findings regarding mutations in the SF-1/1 (-135), SF-1/2 (-45), and SF-1/3 (-95) binding sites demonstrated progressive involvement of the latter on StAR promoter activity in MA-10 cells. In these findings, the $(\mathrm{Bu})_{2} \mathrm{CAMP}$-stimulated fold responses were preserved, indicating that SF-1 elements are important for transcriptional responsiveness but dispensable for cAMP-mediated StAR gene regulation. Also, mutations in the SF-1 elements, at positions -135 and -95 in the rat and at $-105 /-95$ in the human, have been demonstrated to be critical for basal and cAMP responsiveness (Sugawara et al. 1997, Sandhoff et al. 1998, Clark \& Combs 1999). We also observed the relative importance of different SF-1 recognition motifs in MA-10 nuclear proteinDNA binding in EMSA, where the specificity of binding was verified by cold competitors, mutations in the target sites and by SF-1 antibody, an observation in agreement with the role of SF-1 elements in StAR promoter function. Collectively, using sequence- and site-specific mutational analyses, the present data demonstrate the major involvement of $\mathrm{SF}-1 / 3$ in StAR gene expression whereas the SF-1/2 and SF-1/1 recognition sites play lesser roles.

From the results of the current findings, it is apparent that SF-1 is necessary, although not sufficient for complete cAMP responsiveness, since mutations in any of these SF-1 binding sites decreased, but did not abolish, basal and $(\mathrm{Bu})_{2}$ cAMP-mediated StAR reporter activity. Furthermore, a functional cooperation between CRE and SF-1 elements was observed in mediating mouse StAR gene expression, as determined by EMSA and reporter gene analyses. Several lines of evidence suggest that transcription factors either interact and/or cooperate with other transcription factors to regulate transcription of the target genes. In the case of many cAMP-regulated steroidogenic genes that lack a consensus CRE, SF-1 can function as a transcriptional regulator alone (see Introduction) or in concert with other transcription factors. For example, interactions between SF-1 and CCAAT/enhancer binding protein $\beta$ (C/ $\mathrm{EBP} \beta), \mathrm{Sp} 1, \mathrm{CBP} / \mathrm{p} 300$ and SOX9 have been shown to be involved in regulating the mouse
StAR, bovine GYP11A, human P450scc and anti-Mullerian hormone genes respectively (Liu \& Simpson 1997, Monte et al. 1998, de Santa Barbara et al. 1998, Reinhart et al. 1999, Sugawara et al. 2000).

An interesting aspect of the results obtained in these experiments is that a functional proteinprotein interaction exists between GREB/CREM $\tau$ and SF-1 as demonstrated with the mammalian two-hybrid assay. This interaction appeared to be dependent, at least in part, on CREB protein phosphorylation. Studies have demonstrated that treatment of forskolin is capable of increasing SF-1 protein phosphorylation in $\mathrm{Y}-1$ adrenocortical tumor cells (Gyles et al. 2001), and phosphorylation of SF-1 has also been shown to modulate cofactor recruitment (Hammer et al. 1999). Hence, a role for phosphorylation of SF-1 in CREB/CREM $\tau$ and $\mathrm{SF}-1$ protein-protein interactions cannot be excluded. Since the interaction of CREB and SF-1 was impaired by the CREB-M1 ( $\mathrm{Ser}^{133} \mathrm{Ala}$ ), it is possible that $\mathrm{CBP} / \mathrm{p} 300$ (a factor known to interact with both CREB and SF-1 (Monte et al. 1998), and whose interaction with CREB is inhibited by the same mutation) may play an important role in bridging the two transcription factors. Further studies will be required to determine the nature of this interaction, which could be through a direct protein-protein interaction or through the recruitment of co-activators to the StAR promoter. It has been reported that CREB synergizes with other transcription factors for mediation of cAMP responsiveness (Roesler et al. 1995, Carlone \& Richards 1997). Consequently, CREB and SF-1 have been demonstrated to interact synergistically in $\mathrm{R} 2 \mathrm{C}$ rat Leydig tumor cells and additively in rat granulosa cells to confer cAMP responsiveness for the expression of the aromatase gene (Carlone \& Richards 1997). Also, SF-1 and CREB acting in concert have been shown to be involved in the synergistic transactivation of the inhibin $\alpha$ promoter while they have relatively weak effects on transcription individually (Ito et al. 2000).

The 5'-flanking region $(-151 /-1)$ in the mouse StAR promoter has, in addition to several transcription factor binding sites, sites including three CRE half-sites, and appears to be the most important region in transcriptional regulation of the StAR gene. This region possesses putative binding sites for SF-1, C/EBP, GATA, and AP-1, and each has been shown to influence StAR 
promoter function (Caron et al. 1997, Christenson et al. 1999, Reinhart et al. 1999, Silverman et al. 1999, Wooton-Kee \& Clark 2000). Recently, the $-105 /-60 \mathrm{bp}$ region, containing an SF-1, a $\mathrm{C} / \mathrm{EBP} \beta$-AP-1-nuclear receptor half-site, and a GATA-4 binding site, has been shown to function in cAMP responsiveness (Wooton-Kee \& Clark 2000). The G/EBP $\beta-3$ (-81) and GATA-4 (-66) sites have been demonstrated to markedly affect protein-DNA binding and cAMP/folliclestimulating hormone-mediated StAR promoter activity in granulosa cells (Silverman et al. 1999). As indicated above, the SF-1 elements within the region of the mouse (our present data, and Clark \& Combs 1999), rat and human StAR promoters were demonstrated to play important roles in StAR gene function (Sugawara et al. 1997, Sandhoff et al. 1998). Also, the $\mathrm{C} / \mathrm{EBP} \beta$ elements, at positions $-113(\mathrm{C} 1)$ and $-87(\mathrm{C} 2)$ in the murine and -119 and -50 in the human StAR promoters, have been shown to be involved in regulating StAR gene transcription (Christenson et al. 1999, Reinhart et al. 1999). Work is currently underway to assess a potential role for these factors in the interaction and/or cooperation with CREB in cAMPmediated StAR gene transcription.

The results obtained from this (Reinhart et al. 1999, Manna et al. 2002a,b, and the present work) and other (Caron et al. 1997, Sandhoff et al. 1998, Christenson et al. 1999, Silverman et al. 1999, Wooton-Kee \& Clark 2000) laboratories have allowed us to speculate that the combinatorial action of these elements (CRE2/AP-1/C/EBP, SF-1, and GATA) might be involved in the transcriptional regulation of the StAR gene. However, this hypothesis does not exclude the interaction of CREB with other transcription factors or co-activators in addition to SF-1, which may be required for full promoter response. Thus, it is possible that regulation of other steroidogenic genes that lack a consensus CRE and are regulated by cAMP may also be mediated by similar mechanisms.

\section{Acknowledgements}

This investigation was supported in part by NIH grant HD-17481, and with funds from the Robert A Welch Foundation. The authors would like to thank Dr K Morohashi (National Institute for Basic
Biology, Okazaki, Japan) for the generous gift of SF-1 antibody.

\section{References}

Ascoli M 1981 Characterization of several clonal lines of cultured Leydig tumor cells: gonadotropin receptors and steroidogenic responses. Endocrinology 108 88-95.

Cammas FM, Pullinger GD, Barker S \& Clark AJ 1997 The mouse adrenocorticotropin receptor gene: cloning and characterization of its promoter and evidence for a role for the orphan nuclear receptor steroidogenic factor 1. Molecular Endocrinology 11 867-876.

Carlone DL \& Richards JS 1997 Functional interactions, phosphorylation, and levels of $3^{\prime}, 5^{\prime}$-cyclic adenosine monophosphate-regulatory element binding protein and steroidogenic factor-1 mediate hormone-regulated and constitutive expression of aromatase in gonadal cells. Molecular Endocrinology 11 292-304.

Caron KM, Ikeda Y, Soo SG, Stocco DM, Parker KL \& Clark BJ 1997 Characterization of the promoter region of the mouse gene encoding the steroidogenic acute regulatory protein. Molecular Endocrinology 11 138-147.

Christenson LK, Johnson PF, McAllister JM \& Strauss JF III 1999 CCAAT/enhancer-binding proteins regulate expression of the human steroidogenic acute regulatory protein (StAR) gene. Fournal of Biological Chemistry 274 26591-26598.

Chrivia JC, Kwok RP, Lamb N, Hagiwara M, Montminy MR \& Goodman RH 1993 Phosphorylated CREB binds specifically to the nuclear protein CBP. Nature 365 855-859.

Clark BJ \& Combs R 1999 Angiotensin II and cyclic adenosine $3^{\prime}, 5^{\prime}$-monophosphate induce human steroidogenic acute regulatory protein transcription through a common steroidogenic factor-1 element. Endocrinology 140 4390-4398.

Clark BJ, Wells J, King SR \& Stocco DM 1994 The purification, cloning, and expression of a novel luteinizing hormone-induced mitochondrial protein in MA-10 mouse Leydig tumor cells. Characterization of the steroidogenic acute regulatory protein (StAR). Fournal of Biological Chemistry $26928314-28322$.

Clark BJ, Combs R, Hales KH, Hales DB \& Stocco DM 1997 Inhibition of transcription affects synthesis of steroidogenic acute regulatory protein and steroidogenesis in MA-10 mouse Leydig tumor cells. Endocrinology 138 4893-4901.

Della Fazia MA, Servillo G \& Sassone-Corsi P 1997 Cyclic AMP signalling and cellular proliferation: regulation of CREB and CREM. FEBS Letters 410 22-24.

Delmas V, van der Hoorn F, Mellstrom B, Jegou B \& Sassone-Corsi P 1993 Induction of CREM activator proteins in spermatids: down-stream targets and implications for haploid germ cell differentiation. Molecular Endocrinology 7 1502-1514.

Dignam JD, Lebovitz RM \& Roeder RG 1983 Accurate transcription initiation by RNA polymerase II in a soluble extract from isolated mammalian nuclei. Nucleic Acids Research $\mathbf{1 1}$ $1475-1489$.

Dwarki VJ, Montminy M \& Verma IM 1990 Both the basic region and the 'leucine zipper' domain of the cyclic AMP response element binding (CREB) protein are essential for transcriptional activation. EMBO fournal 9 225-232.

Epstein LF \& Orme-Johnson NR 1991 Regulation of steroid hormone biosynthesis. Identification of precursors of a phosphoprotein targeted to the mitochondrion in stimulated rat adrenal cortex cells. Fournal of Biological Chemistry 266 19739-19745.

Eubank DW, Duplus E, Williams SG, Forest G \& Beale EG 2001 Peroxisome proliferator-activated receptor gamma and chicken ovalbumin upstream promoter transcription factor II negatively 
regulate the phosphoenolpyruvate carboxykinase promoter via a common element. Fournal of Biological Chemistry 276 30561-30579.

Fisch TM, Prywes R, Simon MC \& Roeder RG 1989 Multiple sequence elements in the c-fos promoter mediate induction by cAMP. Genes and Development 3 198-211.

Foulkes NS, Mellstrom B, Benusiglio E \& Sassone-Corsi P 1992 Developmental switch of CREM function during spermatogenesis: from antagonist to activator. Nature 355 80-84.

Gonzalez GA \& Montminy MR 1989 Cyclic AMP stimulates somatostatin gene transcription by phosphorylation of CREB at serine 133. Cell 59 675-680.

Gonzalez GA, Menzel P, Leonard J, Fischer WH \& Montminy MR 1991 Characterization of motifs which are critical for activity of the cyclic AMP-responsive transcription factor CREB. Molecular and Cellular Biology 11 1306-1312.

de Groot RP, Delmas V \& Sassone-Corsi P 1994 DNA bending by transcription factors CREM and CREB. Oncogene 9 463-468.

Gyles SL, Burns CJ, Whitehouse BJ, Sugden D, Marsh PJ, Persaud SJ \& Jones PM 2001 ERKs regulate cyclic AMP-induced steroid synthesis through transcription of the steroidogenic acute regulatory (StAR) gene. Fournal of Biological Chemistry 276 34888-34895.

Hammer GD, Krylova I, Zhang Y, Darimont BD, Simpson K, Weigel NL \& Ingraham HA 1999 Phosphorylation of the nuclear receptor SF-1 modulates cofactor recruitment: integration of hormone signaling in reproduction and stress. Molecular Cell $\mathbf{3}$ 521-526.

Ikeda Y, Shen WH, Ingraham HA \& Parker KL 1994 Developmental expression of mouse steroidogenic factor-1, an essential regulator of the steroid hydroxylases. Molecular Endocrinology 8 654-662.

Ingraham HA, Lala DS, Ikeda Y, Luo X, Shen, WH, Nachtigal MW, Abbud R, Nilson JH \& Parker KL 1994 The nuclear receptor steroidogenic factor 1 acts at multiple levels of the reproductive axis. Genes and Development 8 2302-2312.

Ito M, Park Y, Weck J, Mayo KE \& Jameson JL 2000 Synergistic activation of the inhibin alpha-promoter by steroidogenic factor-1 and cyclic adenosine $3^{\prime}, 5^{\prime}$-monophosphate. Molecular Endocrinology 14 66-81.

Jacob AL \& Lund J 1998 Mutations in the activation function-2 core domain of steroidogenic factor-1 dominantly suppresses

PKA-dependent transactivation of the bovine CYP17 gene. Fournal of Biological Chemistry 273 13391-13394.

Lalli E \& Sassone-Corsi P 1994 Signal transduction and gene regulation: the nuclear response to cAMP. Fournal of Biological Chemistry 269 17359-17362.

Lee KA \& Masson N 1993 Transcriptional regulation by CREB and its relatives. Biochimica et Biophysica Acta 1174 221-233.

Liu JS, Park EA, Gurney AL, Roesler WJ \& Hanson RW 1991 Cyclic AMP induction of phosphoenolpyruvate carboxykinase (GTP) gene transcription is mediated by multiple promoter elements. Fournal of Biological Chemistry 266 19095-19102.

Liu Z \& Simpson ER 1997 Steroidogenic factor 1 (SF-1) and SP1 are required for regulation of bovine CYP11A gene expression in bovine luteal cells and adrenal Y1 cells. Molecular Endocrinology 11 127-137.

Lynch JP, Lala DS, Peluso JJ, Luo W, Parker KL \& White BA 1993 Steroidogenic factor 1 , an orphan nuclear receptor, regulates the expression of the rat aromatase gene in gonadal tissues. Molecular Endocrinology 7 776-786.

Manna PR, Pakarinen P, El-Hefnawy T \& Huhtaniemi IT 1999a Functional assessment of the calcium messenger system in cultured mouse Leydig tumor cells: regulation of human chorionic gonadotropin-induced expression of the steroidogenic acute regulatory protein. Endocrinology 140 1739-1751.

Manna PR, Tena-Sempere M \& Huhtaniemi IT $1999 b$ Molecular mechanisms of thyroid hormone-stimulated steroidogenesis in mouse Leydig tumor cells. Involvement of the steroidogenic acute regulatory (StAR) protein. Fournal of Biological Chemistry 274 5909-5918.

Manna PR, Kero J, Tena-Sempere M, Pakarinen P, Stocco DM \& Huhtaniemi IT 2001 Assessment of mechanisms of thyroid hormone action in mouse Leydig cells: regulation of the steroidogenic acute regulatory protein, steroidogenesis, and luteinizing hormone receptor function. Endocrinology 142 319-331.

Manna PR, Dyson MT, Eubank DW, Clark BJ, Lalli E, Sassone-Corsi P, Zeleznik AJ \& Stocco DM 2002a Regulation of steroidogenesis and the steroidogenic acute regulatory protein by a member of the cAMP response-element binding protein family. Molecular Endocrinology 16 184-199.

Manna PR, Huhtaniemi IT, Wang XJ, Eubank DW \& Stocco DM $2002 b$ Mechanisms of epidermal growth factor signaling: regulation of steroid biosynthesis and the steroidogenic acute regulatory protein in mouse Leydig tumor cells. Biology of Reproduction 67 1393-1404.

Meyer TE \& Habener JF 1993 Cyclic adenosine $3^{\prime}, 5^{\prime}$-monophosphate response element binding protein (CREB) and related transcription-activating deoxyribonucleic acid-binding proteins. Endocrine Reviews 14 269-290.

Monte D, DeWitte F \& Hum DW 1998 Regulation of the human $\mathrm{P} 450$ scc gene by steroidogenic factor 1 is mediated by CBP/p300. Fournal of Biological Chemistry 273 4585-4591.

Montminy MR, Sevarino KA, Wagner JA, Mandel G \& Goodman RH 1986 Identification of a cyclic-AMP-responsive element within the rat somatostatin gene. PNAS 83 6682-6686.

Morohashi K, Zanger UM, Honda S, Hara M, Waterman MR \& Omura T 1993 Activation of CYP11A and CYP11B gene promoters by the steroidogenic cell-specific transcription factor, Ad4 BP. Molecular Endocrinology 7 1196-1204.

Parker KL \& Schimmer BP 1997 Steroidogenic factor 1: a key determinant of endocrine development and function. Endocrine Reviews 18 361-377.

Privalle CT, Crivello JF \& Jefcoate CR 1983 Regulation of intramitochondrial cholesterol transfer to side-chain cleavage cytochrome P-450 in rat adrenal gland. PNAS $80702-706$.

Quinn PG 1993 Distinct activation domains within cAMP response element-binding protein (CREB) mediate basal and cAMP-stimulated transcription. Fournal of Biological Chemistry 268 16999-17009.

Reinhart AJ, Williams SC, Clark BJ \& Stocco DM 1999 SF-1 (steroidogenic factor-1) and C/EBP $\beta$ (CCAAT/enhancer binding protein- $\beta$ ) cooperate to regulate the murine StAR (steroidogenic acute regulatory) promoter. Molecular Endocrinology 13 729-741.

Roesler WJ, Graham JG, Kolen R, Klemm DJ \& McFie PJ 1995 The cAMP response element binding protein synergizes with other transcription factors to mediate cAMP responsiveness. Fournal of Biological Chemistry 270 8225-8232.

Sandhoff TW, Hales DB, Hales KH \& McLean MP 1998 Transcriptional regulation of the rat steroidogenic acute regulatory protein gene by steroidogenic factor 1. Endocrinology 139 4820-4831.

de Santa Barbara P, Bonneaud N, Boizet B, Desclozeaux M, Moniot B, Sudbeck P, Scherer G, Poulat F \& Berta P 1998 Direct interaction of SRY-related protein SOX9 and steroidogenic factor 1 regulates transcription of the human anti-Mullerian hormone gene. Molecular and Cellular Biology 18 6653-6665.

Sassone-Corsi P 1995 Transcription factors responsive to cAMP. Annual Review of Cellular and Developmental Biology 11 355-377.

Shea-Eaton W, Sandhoff TW, Lopez D, Hales DB \& McLean MP 2002 Transcriptional repression of the rat steroidogenic acute regulatory (StAR) protein gene by the AP-1 family member c-Fos. Molecular and Cellular Endocrinology 188 161-170. 
Silverman E, Eimerl S \& Orly J 1999 CGAAT enhancer-binding protein $\beta$ and GATA-4 binding regions within the promoter of the steroidogenic acute regulatory protein (StAR) gene are required for transcription in rat ovarian cells. Fournal of Biological Chemistry 274 17987-17996.

Stocco DM \& Clark BJ 1996 Regulation of the acute production of steroids in steroidogenic cells. Endocrine Reviews 17 221-244.

Sugawara T, Holt JA, Kiriakidou M \& Strauss JF III 1996 Steroidogenic factor 1-dependent promoter activity of the human steroidogenic acute regulatory protein (StAR) gene. Biochemistry $\mathbf{3 5}$ 9052-9059.

Sugawara T, Kiriakidou M, McAllister JM, Kallen CB \& Strauss JF III 1997 Multiple steroidogenic factor 1 binding elements in the human steroidogenic acute regulatory protein gene 5 '-flanking region are required for maximal promoter activity and cyclic AMP responsiveness. Biochemistry 36 7249-7255.

Sugawara T, Saito M \& Fujimoto S $2000 \mathrm{Spl}$ and SF-1 interact and cooperate in the regulation of human steroidogenic acute regulatory protein gene expression. Endocrinology 141 2895-2903.

Waterman MR 1994 Biochemical diversity of cAMP-dependent transcription of steroid hydroxylase genes in the adrenal cortex. Fournal of Biological Chemistry 269 27783-27786.

Waterman MR 1995 A rising StAR: an essential role in cholesterol transport. Science 267 1780-1781.
Wooton-Kee CR \& Clark BJ 2000 Steroidogenic factor-1 influences protein-deoxyribonucleic acid interactions within the cyclic adenosine 3,5-monophosphate-responsive regions of the murine steroidogenic acute regulatory protein gene. Endocrinology 141 $1345-1355$.

Yamamoto KK, Gonzalez GA, Menzel P, Rivier J \& Montminy MR 1990 Characterization of a bipartite activator domain in transcription factor CREB. Cell $60611-617$.

Yu RN, Ito M \& Jameson JL 1998 The murine Dax-1 promoter is stimulated by SF-1 (steroidogenic factor-1) and inhibited by COUP-TF (chicken ovalbumin upstream promoter- transcription factor) via a composite nuclear receptor-regulatory element. Molecular Endocrinology 12 1010-1022.

Zhang P \& Mellon SH 1996 The orphan nuclear receptor steroidogenic factor-1 regulates the cyclic adenosine $3^{\prime}, 5^{\prime}$-monophosphate-mediated transcriptional activation of rat cytochrome P450c17 (17 alpha-hydroxylase/c17-20 lyase). Molecular Endocrinology 10 147-158.

Received in final form 27 November 2002 Accepted 6 December 2002 